\title{
Micro-scale genetic heterogeneity and structure in coral recruitment: fine-scale patchiness
}

\author{
Daniel A. Brazeau ${ }^{1, *}$, Paul W. Sammarco ${ }^{2,3}$, Amy D. Atchison ${ }^{2,3}$ \\ ${ }^{1}$ Department of Pharmaceutical Sciences, University at Buffalo, Buffalo, New York 14260-1200, USA \\ ${ }^{2}$ Louisiana Universities Marine Consortium (LUMCON), Chauvin, Louisiana 70344, USA \\ ${ }^{3}$ Department of Oceanography and Coastal Sciences, Louisiana State University, Baton Rouge, Louisiana 70803, USA
}

\begin{abstract}
Coral reefs have recently suffered severe environmental perturbations. Genetic variability and structure in coral populations is important in determining their survival and adaptation and can be influenced by larval settlement/recruitment. Here, we assess the genetic heterogeneity of Agaricia agaricites coral recruits at 3 spatial scales on the East Flower Garden Bank, Gulf of Mexico. Racks with settlement plates were placed at each of 3 sites, at $23 \mathrm{~m}$ depth, arranged in a circular pattern, 10s of meters apart. Three racks were placed within each site, several meters from each other. Each rack held 5 terracotta settling plates, several centimeters apart. Highly polymorphic markers for amplified fragment length polymorphisms (AFLP) were used to assess genetic structure among recruits: among sites, racks, and plates. Four sets of AFLP primers yielded 164 polymorphic markers. The assignment-based statistical programs AFLPOP and STRUCTURE assigned coral spat back to their original sites (home populations) at levels of between 63.3 and $99.8 \%$. Recruit populations exhibited clear, consistent genetic heterogeneity at a scale of 10s of meters. The levels of assignment back to rack home populations were broader, ranging from 32.5 to $96.5 \%$. Highest rates of selfassignment/identification of distinct/separate populations occurred at the smallest spatial scale, i.e. the plates (53.7 to $96.5 \%$ ). Genetic relatedness among recruits was highest and patchy at a scale of $10 \mathrm{~s}$ of centimeters, more variable at a scale of meters, and still detectable at a scale of $10 \mathrm{~s}$ of meters. Genetic variability in these recruits was high. Recruitment was probably local, from corals in the immediate vicinity, and with limited mixing.
\end{abstract}

KEY WORDS: Coral · Agaricia agaricites · Genetic assignment · AFLP · Recruitment · Dispersal

\section{INTRODUCTION}

Scleractinian corals, like many marine invertebrates, are sessile with motile planktonic larvae that settle, metamorphose, and live most of their lives at a single point on the substrate. Dispersal is effected via primarily passive larvae and is, therefore, determined by currents, larval longevity, competence to settle, larval behavior, and the availability and suitability of new habitats. Thus, for many sessile marine invertebrates, pre-settlement factors often determine the abundance and genetic structure of adult populations (Lasker et al. 1998). Survival during environmental perturbations, such as temperature changes and bleaching, is also partially dependent upon population size, and adult populations often play an important role in local recruitment, yielding positive density-dependent recruitment relationships between adult densities and recruitment pools (Hughes \& Tanner 2000, Vermeij \& Sandin 2008).

The genetic structure and variability within a population determines, in part, its ability to adapt to a changing environment. If the recruitment pool is largely derived from local adult populations, local genetic variability will be low; recruits, however, may be very well-adapted to the local conditions and have a high survival rate - as long as environmental conditions remain unchanged. If the conditions change, however, and a sufficient number of individuals do not survive, the population could locally or globally be- 
come extinct (Boyce 1992). Conversely, if genetic variability is high, some members of the population may survive the perturbation and the population as a whole may become better adapted to withstand future perturbations (Knowlton \& Jackson 1993). Environmental changes can occur across a large variety of spatial scales, from global (e.g. increasing seawater temperatures inducing bleaching, affecting an entire reef) to intermediate (the dragging of an anchor across a reef, causing damage on scales 10 s of meters to meters), down to the micro-scale (e.g. micro-competitive interactions between a patchily distributed invasive species and a native coral, affecting corals at scales of centimeters to 10s of centimeters) (Connell et al. 1997, Hughes et al. 1999). The degree and structure of genetic variability within a population at a given scale can determine its probability of survivorship in response to the scale of the perturbation (Mace \& Lande 1991, Fahrig 2002).

Genetic studies have indicated that coral recruitment for many species is often local (Ayre \& Hughes 2000, Tioho et al. 2001, Brazeau et al. 2005). In addition, many studies indicate that significant genetic heterogeneity and heterozygote deficiencies are common among populations (Watts et al. 1990, Smith et al. 2004, Veliz et al. 2006). Factors such as limited larval movement, nearby matings, and limited larval mixing may be common in many marine invertebrate species. Even for species with larvae capable of long-distance dispersal, data suggest that larval mixing during the planktonic stage may be limited (Taylor \& Hellberg 2003, Cowen et al. 2006, Severance \& Karl 2006), often resulting in populations with chaotic patchiness (Moberg \& Burton 2000, Veliz et al. 2006). Larval mixing can also be limited by oceanographic features that retain larvae near their source population, slowing the forces of diffusion and advection through eddying and entrainment of larvae (e.g. Sammarco \& Andrews 1988, Sammarco 2004, Pineda et al. 2007). The reduction of larval dispersal can contribute to the isolation of populations, potentially further reducing the probability of survival of a population undergoing environmental stress.

The question of larval movement in sessile marine invertebrates defines the ability of a relatively remote population to be able to regenerate in the event of an environmental perturbation that might otherwise cause near or complete local extinction in that population. Such communities are almost entirely dependent upon recruitment from distant populations. This is particularly the case for corals. Adult population structure, dynamics, and genetics are largely determined by factors affecting larval dispersal, settlement, and recruitment. The genetic structure of recruits within a habitat is indicative of the relative contributions of external versus local sources of larvae and provides insight into levels of larval mixing in the water column prior to settlement. Settlement and recruitment can, of course, be highly variable through time with respect to numbers and sources of larvae (Lecchini \& Galzin 2003, Brunel \& Boucher 2006).

Genetic assignment tests have proven quite useful in obtaining answers to ecological questions about genetic affinities among individuals and populations (Manel et al. 2005). These recently developed tests have yielded results that more directly estimate numbers of migrants among populations ( $N_{\mathrm{m} i}$ Paetkau et al. 2004) than earlier traditional numerical parameters, like estimates of genetic distance among individuals or populations. Assignment tests are most powerful for, and particularly sensitive to, identifying members of different populations when each individual can be characterized by numerous genetic markers; such tests provide a measure of genetic heterogeneity and structure, but indirectly. Assignment tests represent an alternative approach to traditional genetic tests $\left(F_{\mathrm{ST}}\right)$ and markers, which provide good estimates of genetic structure, but sub-optimal estimates of individual movements and connectedness. Statistical population assignment tests work particularly well with molecular genetic techniques capable of generating numerous markers, such as amplified fragment length polymorphisms (AFLPs; Campbell et al. 2003). He et al. (2004) have remarked that assignment tests for individuals based on highly polymorphic genetic markers are among the most promising methods available to estimate contemporary long-distance dispersal. The 2 statistical assignment techniques we used here are AFLPOP v. 1.1 (Duchesne \& Bernatchez 2002), a statistical analytical procedure designed particularly to analyze data generated by AFLPs, and STRUCTURE v. 2.0 (Pritchard et al. 2000). We previously reported on the development of these techniques and their application to the analysis of coral spat in a Caribbean coral (Brazeau et al. 2005). We have now expanded our use of these techniques and applied them at a much higher resolution to investigate fine genetic structure at spatial scales that have not been examined before.

In the present study, we examine the level of genetic homogeneity (or affinity) among coral recruits that have settled onto experimental settlement substrata at a number of spatial scales over the course of a single year. The purpose of this is to provide greater insight into the degree of genetic patchiness that might occur among neighboring recruits. As our target organism, we used Agaricia agaricites, a brooding coral that is a dominant pioneer species in natural, healthy Caribbean coral reef communities and which recruits in high numbers (Sammarco 1980, 1987, 2004, Riegl et al. 2003). It is also well represented in the adult coral com- 
munity of our study region - the NOAA Flower Garden Banks (FGB) National Marine Sanctuary, northern Gulf of Mexico (Baggett \& Bright 1985, Brazeau et al. 2005, Shearer \& Coffroth 2006). We examined the genetic structure of coral recruits at 3 levels of spatial resolution-10s of meters, meters, and centimeters. We used AFLP markers to investigate the genetic relatedness of coral spat that settled onto terracotta settling plates deployed at these spatial scales on the East FGB (Brazeau et al. 2005; see also Tioho et al. 2001, Gilmour 2002). Our analysis is based upon recruit samples only; adult colonies were not sampled in the present study. An earlier study (Brazeau et al. 2005) had shown that recruits in this area were not genetically distinguishable from local adult colonies. Unfortunately, we cannot directly combine the adult data from the earlier study with the present data, since the band-scoring methods used are not the same and the adult samples are no longer available.

\section{MATERIALS AND METHODS}

Study site. The study was conducted on the East FGB $\left(27^{\circ} 54^{\prime} 32.8^{\prime \prime} \mathrm{N}, 93^{\circ} 35^{\prime} 35.55^{\prime \prime} \mathrm{W}\right)$ at Buoy \#2, at a depth of $23 \mathrm{~m}$. This area has a high species diversity of corals, generally with a high percentage of live cover (>50\%; Pattengill-Semmens \& Gittings 2003, Aronson et al. 2005). The FGB is separated by $\geq 640 \mathrm{~km}$ of open ocean from other well-developed coral reefs (Hagman et al. 1998, Sammarco et al. 2004), with the closest reef system being Lobos-Tuxpan, located $13 \mathrm{~km}$ off Cabo Rojo, Mexico.

Experimental design. The experiment followed a Model II, 2-level, nested orthogonal design. The first experimental factor was the specific area where coral spat were to be collected, which we shall refer to as 'sites'. Three sites (A, B, and C) were chosen around the mooring for Buoy \#2, at a distance of about $10 \mathrm{~m}$ from the buoy and distributed in a radial fashion at approximately equal distances ( 23 m) from each other (Fig. 1). The second factor was 'racks'. Three racks (1,2 and 3) were deployed at distances of approximately 1 to $2 \mathrm{~m}$ from each other within a site. The third factor was the replicate 'plates', which were mounted on and nested within racks, at a distance of $2 \mathrm{~cm}$ from each other. Each rack held 5 plates, mounted on pins.

Settlement plates were made of terracotta tiles $15 \times 15 \times 1.3 \mathrm{~cm}$ in size.
Settling substratum of this size is appropriate for coral larvae, since they are coarse-grained organisms (Levins 1968); that is, they cannot perceive the environment further away from themselves for more than perhaps one body length or less (as opposed to finegrained organisms, which sense their environment as multi-faceted over greater distances and are able to perceive larger scale variation in it). Thus, their sphere of perception is most likely several millimeters. It is not the purpose of the present paper to consider the advantages and disadvantages of various settling substrates or to review the extensive literature in this area. The suitability of these tiles for settlement in the field and in the laboratory has been demonstrated experimentally in numerous earlier studies in both the Caribbean (Quinn \& Kojis 2005) and the Indo-Pacific (e.g. Harriott \& Banks 1995, Atrigenio \& Alino 1996, Maida et al. 2001). McGuire (1998) found that survival and growth of coral spat was higher on ceramic tiles than on other artificial substrata (e.g. glass, PVC, concrete, coral/limestone blocks). This effect, however, has not been reported in other studies; at least one other experiment has shown that this is not necessarily always the case (Adjeroud et al. 2007). We have, however, found that this substrate is suitable for our purposes (P. W. Sammarco unpubl.). In addition, if enhancement of settlement was occuring, the effect was distributed uniformly within and between all plates, in all treatments.

The plates were drilled in the center to accommodate mounted marine-grade stainless steel all-thread pins.

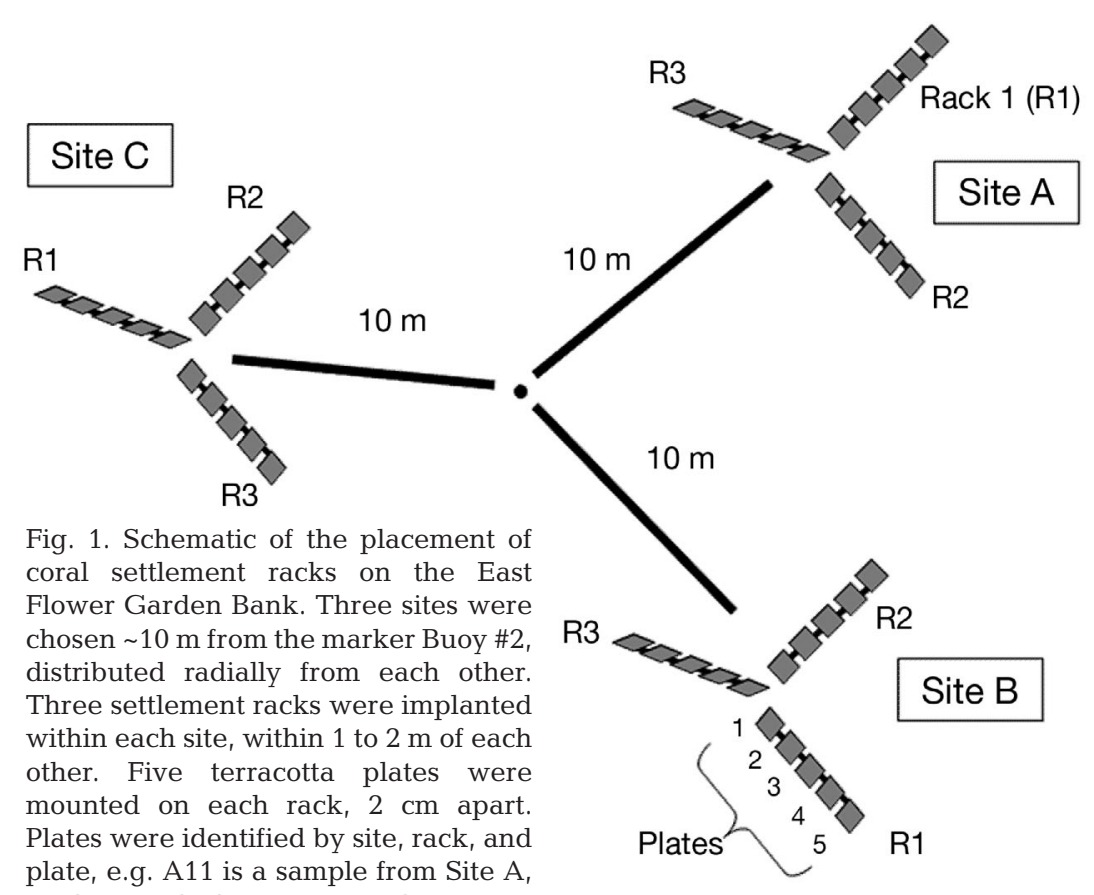

Rack 1, and Plate 1. Note: diagram is not to scale 
Thus, the plates could be held off the benthic substratum. The plates were secured to the pins with 2 sets of Teflon washers, flat steel washers, lockwashers, and steel nuts. Teflon washers were placed as insulators between the flat washers and plates.

Racks holding the pins and plates were constructed of galvanized steel angle iron, $1 \mathrm{~m}$ in length. Holes (1.5 $\mathrm{cm}$ in diameter) were drilled into the ends of the racks to accommodate $1.25 \mathrm{~cm}$ diameter steel reinforcement bars, which were driven $1 \mathrm{~m}$ into the reef substratum to secure them (similar to the deployment techniques used in Sammarco 1991). The rack was held in place by stainless steel hose clamps at each end, clamping the rack down and securing it to the bars. The orientation of the rack provided a plate angle $45^{\circ}$ from a horizontal position, known in some cases to be preferred for settlement by coral larvae (Carleton \& Sammarco 1987). Plates were mounted with the corrugated side downward.

Racks were deployed on 7 and 8 July 1997 and retrieved on 23 June 1998. Plates were detached, labeled, placed in labeled freezer bags with a high salt DNA preservation buffer, and placed in a shipboard freezer. They were then returned to the laboratory and stored at $-20^{\circ} \mathrm{C}$. Plates were examined for coral recruits visually using a Wild-Heerburg dissecting microscope. Small tissue samples were taken from each coral recruit, as small as $40 \mu \mathrm{m}$ in diameter, for molecular genetic analysis and processed as described below.

AFLPs. For each plate with 10 or more recruits, at least 10 recruits were randomly chosen for analysis. High-molecular-weight genomic DNA was isolated from each individual recruit using the Wizard SV Genomic DNA Purification System, as per manufacturer's protocol (Promega) for animal tissues. Prior to DNA isolation, samples were macerated lightly in SED buffer and spun at $16000 \mathrm{~g}$ for $5 \mathrm{~min}$ to pellet the zooxanthellae and debris from the homogenate. Prior to AFLP analysis, all samples were checked for zooxanthellar DNA contamination using stringent PCR techniques (Brazeau et al. 2005, see also Amar et al. 2008).

Samples were processed in large, random lots containing members from all blocks, to uniformly distribute any error in an unbiased fashion that may have been introduced by reaction conditions between populations. In addition, all PCR reactions were done using a single machine and the same thermal cycling profiles. Finally, the final selective PCR step was repeated 3 times for each sample. A band was scored as present only if it appeared in 2 or more of the 3 replicates. AFLPs, like other multi-locus techniques, generate many bands, a portion of which may appear as a function of specific reaction conditions. Here, we exercised extra caution in processing samples through all steps of the procedure in order to maximize repeatability of results.

AFLP analysis was performed following protocols based upon Vos et al. (1995), with modifications for working with minute DNA samples. Briefly, DNA was digested and ligated to the adapters (EcorRI: 5'-CTC GTA GAC TGC GTA CC-3', 3'-CAT CTG ACG CAT GGT TAA-5'; MseI: 5'-GAC GAT GAG TCC TGA G3', 3'-TA CTC AGG ACT CAT-5') for $1 \mathrm{~h}$ at room temperature and then at $16^{\circ} \mathrm{C}$ overnight with $1 \mathrm{U}$ of MseI (New England Biolabs), 5 U EcoRI (Promega Corp), and 1 WeissU $\mathrm{T}_{4}$ DNA ligase in $1 \times$ ligase buffer (0.1 mM ATP) with 0.5 M NaCl. Digested/ligated DNA fragments were diluted 20-fold for the first PCR amplification. Primers used in the 'pre-selective amplification' were complementary to the adapters, with the addition of a single nucleotide-an 'A' for the EcoRI adapters and a ' $\mathrm{C}$ ' for the MseI adapters. Five microliters of the diluted restriction-ligation reaction was added to $15 \mu$ l of the PCR mix ( $200 \mu \mathrm{M}$ each deoxyribonucleotide triphospate [dNTP], $1 \times$ PCR buffer, $3 \mathrm{mM}$ $\mathrm{MgCl}_{2}, 0.275 \mu \mathrm{M}$ each primer, and $0.5 \mathrm{U}$ MasterTaq (Eppendorf). The pre-selective amplification program consisted of an initial cycle of $72^{\circ} \mathrm{C}$ for 2 min (to complete the ligation of the synthetic adapters), followed by 20 cycles of $94^{\circ} \mathrm{C}$ for $20 \mathrm{~s}, 56^{\circ} \mathrm{C}$ for $30 \mathrm{~s}$, and $72^{\circ} \mathrm{C}$ for $2 \mathrm{~min}$, with a final extension of $72^{\circ} \mathrm{C}$ for $2 \mathrm{~min}$ and $60^{\circ} \mathrm{C}$ for $30 \mathrm{~min}$ (final incubation). The pre-selective PCR products were diluted 10-fold for use in the final 'selective amplifications'.

Primers used in the selective PCR had the same sequences as the pre-selective primers, with the addition of 2 additional nucleotides at the 3 '-end and a fluorescent moiety (FAM) tag at the 5 '-end. Five microliters of the diluted pre-selective PCR reaction products were added to $15 \mu$ l of the PCR mix $(200 \mu \mathrm{M}$ of each dNTP, $1 \times$ PCR buffer with $3 \mathrm{mM} \mathrm{MgCl}_{2}, 0.275 \mu \mathrm{M}$ ECoRI primer, $0.275 \mu \mathrm{M}$ MseI primer, and 0.5 U MasterTaq). The selective amplification program consisted of an initial cycle of $94^{\circ} \mathrm{C}$ for $2 \mathrm{~min}, 94^{\circ} \mathrm{C}$ for $20 \mathrm{~s}, 66^{\circ} \mathrm{C}$ for $30 \mathrm{~s}$, and $72^{\circ} \mathrm{C}$ for $2 \mathrm{~min}$. This was followed by 9 cycles of $94^{\circ} \mathrm{C}$ for $20 \mathrm{~s}, 66^{\circ} \mathrm{C}$ for $30 \mathrm{~s}$ (decreasing $1^{\circ} \mathrm{C} \mathrm{cycle}^{-1}$ ), and $72^{\circ} \mathrm{C}$ for $2 \mathrm{~min}$. The treatments to follow were another 20 cycles of $94^{\circ} \mathrm{C}$ for $20 \mathrm{~s}, 56^{\circ} \mathrm{C}$ for $30 \mathrm{~s}$, and $72^{\circ} \mathrm{C}$ for $2 \mathrm{~min}$, with $72^{\circ} \mathrm{C}$ for $2 \mathrm{~min}$, with a final incubation step at $60^{\circ} \mathrm{C}$ for $30 \mathrm{~min}$. Products for the selective PCR were run on an Amersham MegaBACE 1000 96 capillary sequencer. Resulting electropherograms were analyzed using SoftGenetics GeneMarker (v. 1.51) for bands ranging from 50 to $500 \mathrm{bp}$ in size.

Statistical analyses and procedures. Two assignmentbased analyses were used to assess the genetic relatedness of the recruits collected from the settlement plates, AFLPOP (v. 1.0; Duchesne \& Bernatchez 2002) and STRUCTURE (v. 2.2; Paetkau et al. 2004), since 
both programs are in common use and use different algorithms for population assignment. AFLPOP examines the AFLP banding patterns-presence/absence data, calculating log-likelihood values for any individual's membership in a reference population. The program allocates each individual to the population with the highest likelihood given the individual's genotype (Duchesne \& Bernatchez 2002, He et al. 2004). We used the 'simulation-many iterations' procedure of AFLPOP to assign individual recruits to populations based upon marker frequencies calculated from the entire data set (without that individual; commonly referred to as the 'leave-one-out' procedure). The program then outputs the likelihoods and allocation decision for that spat. This procedure was repeated for every individual spat. The threshold within the program for assigning the individual to a population was set to a log-likelihood value of 1.0. This is a stringent and conservative threshold, i.e. assignment of a sample to a population was not made unless the probability of the given assignment was 10 times more likely than the next most probable assignment. If this threshold was not met, the individual was not assigned to any population and was designated as a case of 'criteria not met' (CNM). Assigning a spat to the CNM category does not necessarily imply that it was not derived from, or does not belong to, a local population. It merely denotes that there are 2 or more populations with similar probabilities of assignment (i.e. a $<10$-fold difference between itself and a population). One interpretation of the CNM category would be that all individuals assigned to CNM were not derived from the same population that gave rise to most of the recruits. This would certainly over-estimate the number of recruits that are not genetically homogeneous. Using these data, it would be difficult to determine whether an individual is derived from a non-local population. This would require setting an arbitrary frequency against which to consider the allocation level for a given individual. Such would also require the availability of banding data from all adults in the population. Thus, we did not attempt to make this distinction in the present study.

STRUCTURE uses Bayesian techniques and Monte Carlo simulations to assign samples to populations. Unlike AFLPOP, in which assignment is based solely upon marker frequencies, STRUCTURE makes assignments that minimize deviations from the Hardy-Weinberg (H-W) equilibrium, which assumes that the population giving rise to the recruits constitutes a large, randomly mating population. Using this approach, the program calculates probabilities of individual assignment, estimates of $F_{\mathrm{ST}}$, and probable relationships of paternity, grand-paternity, etc. The program can accommodate dominant marker data, such as those generated by our AFLP technique. The entire data set was subjected to several preliminary runs in order to evaluate parameter estimates used by Markov chain-Monte Carlo (MCMC) iterations for stability. STRUCTURE also called for definition of the parameter MIGPRIOR before running. This parameter was the prior probability of a spat being identified as coming from an external source. It was run at 2 levels, for comparative purposes, 0.05 and 0.50 , taking into account different potential estimated migration rates. Once these parameters were set, data were analyzed using a burn-in period of 500000 iterations, followed by another 100000 MCMC repetitions.

Statistical analyses were performed on the recruit populations at several different spatial scales. That is, all samples were first run and assigned to the 3 experimental sites. Then, data were compared between racks within sites, and, after that, between plates within a rack.

There were a large number of markers generated in the present study by AFLP techniques, and the number of spat per plate was sometimes small. For this reason, we first performed an AFLPOP numerical analysis on the data with the spat (samples) randomly assigned to sites, racks, and plates. The purpose of this was to determine whether spurious, misleading patterns of population subdivision might be generated from the various combinations of and comparisons between markers.

\section{RESULTS}

A total of 227 coral recruits were collected from 16 plates. Of these, $89 \%$ or 203 of the recruits yielded scorable AFLP bands (Table 1). Twenty-four of the recruits were discarded due to low DNA yields resulting in PCR failure. Other than this, we experienced no sample processing problems with tissues from the sampled coral spat.

Tissue from the coral spat was examined using 4 sets of AFLP primers. This yielded 164 polymorphic markers

Table 1. Agaricia agaricites. Total number of processed samples from the racks and plates in the present study, and the resultant number of coral spat used for amplified fragment length polymorphism analysis. Seven of 9 racks and 16 of 45 plates $(35.5 \%)$ had sufficient numbers of recruits $(>10)$ to allow analysis

\begin{tabular}{|lccc|}
\hline Site & Racks & Plates & Recruits \\
\hline A & 2 & 9 & 97 \\
B & 2 & 2 & 22 \\
C & 3 & 5 & 84 \\
Total & 7 & 16 & 203 \\
\hline
\end{tabular}




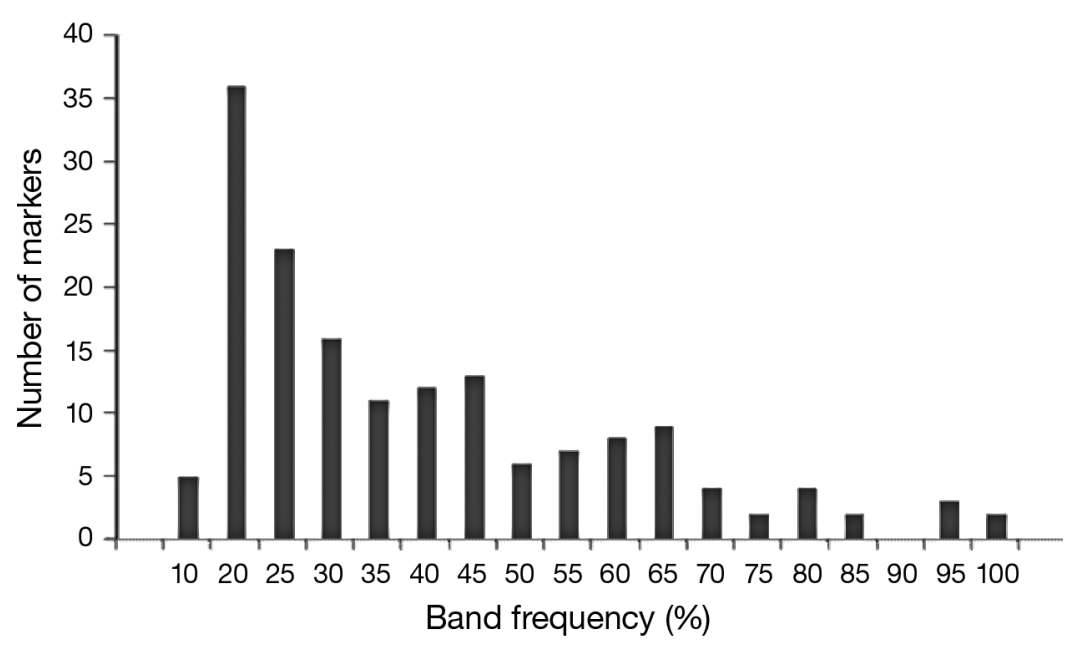

Fig. 2. Agaricia agaricites. Distribution of amplified fragment length polymorphism (AFLP) band frequencies. Bands ranged from 65 to $405 \mathrm{bp}$ in size. Of the

164 markers in the present study, $83.5 \%$ had frequencies from 10 to $50 \%$

$99.8 \%$ of the recruits were assigned by the analysis back to the plates from which they were collected, suggesting considerable genetic homogeneity within plates and significant heterogeneity among plates. Across each run, only $0.2 \%$ of the recruits were assigned to the CNM category; (i.e. they could not be assigned to any plate with a probability 10-fold greater than the next most likely plate; Table 2). Thus, of the 203 recruits assayed, only 1 or 2 could be considered to have come from outside the population.

Similarly, analysis of the entire data set using STRUCTURE indicated that the inferred number of populations $(k)$ was 1, suggesting that all samples originated from 1 homogeneous source i.e. that the recruits were likely derived

that could be compared between individual spat. Bands that occurred in $<5 \%$ of the spat were not used in the analysis (Fig. 2). The overall mean frequency of markers per individual was 0.28 (SD $=0.11$; range $=0.05$ to 0.55 ; mode $=0.37$ ). On average, each individual had 28 markers of the 164 found in the entire population.

The 2 types of analyses used-AFLPOP and STRUCTURE - generally yielded similar patterns of genetic affinity, or heterogeneity, between coral spat, and similar patterns of relationships between spat considered at the spatial scales of site, rack, and plate. In general, the STRUCTURE program yielded higher levels of genetic heterogeneity between the spat considered at all levels than did AFLPOP. In addition, the level of this heterogeneity increased when the MIGPRIOR value used in STRUCTURE analysis was increased from 0.05 to 0.5 .

The randomized data set analyzed via AFLPOP did not reveal any type of population structure (Fig. 3a), indicating that the patterns observed in the true data set were not simply due to the spurious outcome of using large numbers of markers to detect patterns. For all plates, the most common assignment was to the CNM category (Table 2), indicating that samples could not be assigned to any single population with a high likelihood (i.e. a 10-fold greater probability than the next best population fit). As one might have expected, there were few cases of self-assignment, or assignment of an individual spat back to the plate from which it was collected, using the randomized data set.

The AFLPOP analysis of the actual (non-randomized) data set revealed significant genetic structure among recruits on the plates (Fig. 3b; all plates were used here) i.e. the recruits collected for the same plate exhibited significant genetic affinity to each other. An average of from a single source. Most importantly for this analysis, however, both the AFLPOP and STRUCTURE analyses indicated that the samples were not distributed homogeneously among the settling plates.

Both assignment analyses (AFLPOP and STRUCTURE) yielded self-assignments of spat back to their original settlement site (A, B, or C) at a relatively high rate, ranging from 69.5 to $97.5 \%$ (Fig. $4 \mathrm{a} \&$ b, respectively). When using STRUCTURE, these relatively high rates of self-assignment decreased only slightly when the MIGPRIOR parameter - again, the prior probability of a spat being identified as coming from an external source - was increased 10-fold from 0.05 (Fig. 4b) to 0.5 (Fig. $4 \mathrm{c}$ ) (the default setting is MIGPRIOR is 0.05). Those samples not assigned to their original settled population were assigned by STRUCTURE to populations associated with the other 2 sites (areas of rack deployment) at generally equal frequencies. AFLPOP indicated that only $4.7 \%$ of the spat could not be assigned to any given site.

When considering the racks, Site C was used because only at this site was the sample size (number of spat) sufficient for analysis. On racks from this site, the rates of self-assignment of coral recruits were high (ranging from 57.5 to $100 \%$; Fig. 5a) when analyzing via AFLPOP. Once again, this indicated that genetic heterogeneity among coral recruits was sufficient to allow high assignment of recruits back to the racks from which they were collected. This pattern was mimicked very closely in the STRUCTURE analysis (Fig. 5b). Even when setting the probability that an individual is an immigrant to the population to $50 \%$ (i.e. adjusting the MIGPRIOR parameter), the rates of self-assignment decreased; however, the overall pattern was retained (Fig. 5c). 
a

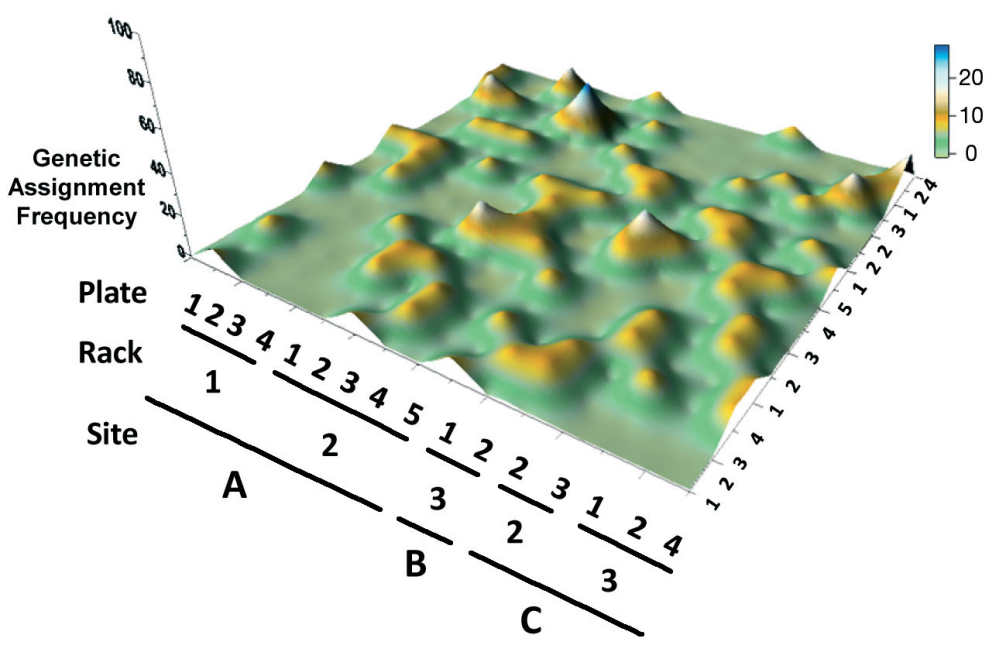

b

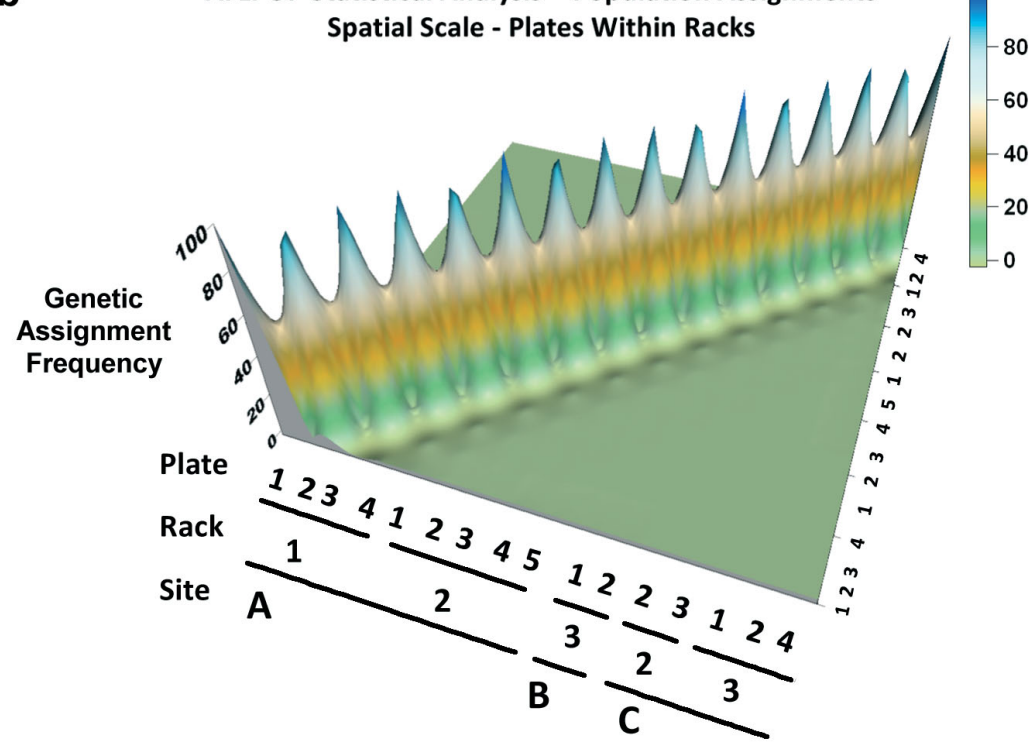

Fig. 3. Agaricia agaricites. (a) AFLPOP genetic assignment of coral recruits, with population identifiers. Data randomized to test for anomalies or spurious patterns derived from analysis. Data shown in percent (\%). Correct allocation of coral spat back to their reference/original populations are indicated by peaks along the diagonal. Note the lack of genetic affinity down the diagonal of the matrix, the general lack of pattern in assignment throughout the table, and the low frequencies of assignment, indicating a random assignment of spat to populations. (b) AFLPOP assignment test as in Panel a, with the actual data set, with coral spat samples being identified at the spatial scale of settlement plates within racks within sites (10s of centimeters). See Table 2 for frequencies of samples that could not be assigned to any population with a probability 10 -fold greater than the next most likely population assignment, designated 'criteria not met' (CNM)

STRUCTURE indicated that the frequency of assignment of coral spat to populations different from their own, at the rack level of resolution (plates combined), was relatively low. Those frequencies ranged from 3.5 to $42.3 \%$.
Finally, even in considering the genetic structure found among spat on different plates within a site (Site A was the only site with sample sizes large enough for analyses), differences between these micro-populations were great. Heterogeneity was high (Fig. 6a). Assignments of spat by the program back to their original settlement populations on individual plates were highest in the AFLPOP analysis. The frequencies of these self-assignments ranged from 99.3 to $100 \%$. There were no assignments from one plate to another plate. All unassigned coral recruits fell into the CNM category at the $<1.0 \%$ level (Table 3). STRUCTURE yielded results that were somewhat more conservative using a default setting of MIGPRIOR = 0.05 (Fig. 6b) and even more conservative using a value of 0.50 (Fig. 6c). Resultant $F_{\mathrm{ST}}$ values are shown in Table 4. Self-assignments of spat to their original plates were lower, ranging from 53.7 to $96.5 \%$. The assignment of coral recruits to plates other than their original plate were, on average, $1.7 \%$ and ranged from $3.5 \%$ (Rack 1, Plate 3 ) to $46.3 \%$ (Rack 1, Plate 4).

\section{DISCUSSION}

The principle finding of the present study was the identification of high levels of genetic heterogeneity in coral spat settling on the experimental plates. Heterogeneity was evident even when considering spat populations at several different spatial scales-from $10 \mathrm{~s}$ of centimeters to $10 \mathrm{~s}$ of meters. It would appear that, at least for Agaricia agaricites, larval dispersal is highly localized, or at least there may be aggregation of genetically similar larvae in the water column during the dispersal process. Based upon the presence/absence of AFLP bands, both of the population assignment programs used here were able to assign recruits back to their sites, racks, or plates of collection with very high probabilities and levels of confidence. Thus, the coral spat populations were clearly heterogeneous at a scale of 10 s of meters. Recruits were correctly assigned to sites of collection at a rate of nearly $95 \%$ by 
Table 2. Agaricia agaricites. AFLPOP genetic assignment of coral recruits, with population identifiers, using the same data set-randomized and non-randomized - to test for anomalies or spurious patterns resulting from the analysis (see Fig. 3). Shown are coral spat that could not be assigned to any site with a probability 10 -fold greater than the next most likely population assignment, designated 'criteria not met' (CNM). The minimum log-likelihood difference for this analysis was set to 1.0. These CNM frequencies were extraordinarily high, ranging from 30 to $70 \%$, indicating random assignment of spat to populations. No obvious pattern resulted. The frequencies in the second column represent CNM values from the standard, non-randomized data set. Note the frequencies of assignment to this category are 2 orders of magnitude lower, indicating that almost all spat could be assigned to populations

\begin{tabular}{|c|c|c|c|}
\hline & \multirow[t]{2}{*}{ Plate } & \multicolumn{2}{|c|}{ CNM $(\%)$} \\
\hline & & $\begin{array}{l}\text { Randomized } \\
\text { samples }\end{array}$ & $\begin{array}{c}\text { Standard } \\
\text { samples }\end{array}$ \\
\hline \multicolumn{4}{|l|}{ Site A } \\
\hline \multirow[t]{4}{*}{ Rack 1} & 1 & 40.00 & 0.18 \\
\hline & 2 & 30.00 & 0.29 \\
\hline & 3 & 60.00 & 0.21 \\
\hline & 4 & 50.00 & 0.33 \\
\hline \multirow[t]{5}{*}{ Rack 2} & 1 & 40.00 & 0.21 \\
\hline & 2 & 60.00 & 0.09 \\
\hline & 3 & 50.00 & 0.63 \\
\hline & 4 & 70.00 & 0.75 \\
\hline & 5 & 30.00 & 0.02 \\
\hline \multicolumn{4}{|l|}{ Site B } \\
\hline \multirow[t]{2}{*}{ Rack 3} & 1 & 40.00 & 0.03 \\
\hline & 2 & 40.00 & 0.02 \\
\hline \multicolumn{4}{|l|}{ Site C } \\
\hline \multirow[t]{2}{*}{ Rack 2} & 2 & 60.00 & 0.10 \\
\hline & 3 & 70.00 & 0.10 \\
\hline \multirow[t]{3}{*}{ Rack 3} & 1 & 50.00 & 0.06 \\
\hline & 2 & 50.00 & 0.01 \\
\hline & 4 & 60.00 & 0.05 \\
\hline
\end{tabular}

AFLPOP and of $69 \%$ by STRUCTURE analysis. Even when the probability of immigration used in STRUCTURE was increased 10-fold, the probability of correct assignment decreased by only $7 \%$; from 69 to $63 \%$.

The fact that AFLPOP yielded values of selfassignment of spat back to populations on their original racks of $>96 \%$ indicated that patterns of genetic heterogeneity were clear at the spatial scale of the racks (meters). Although STRUCTURE yielded somewhat lower values, i.e. $76 \%$ (70\% with MIGPRIOR set to 0.5), they were still significant, indicating strong population structure at this scale. This population structure continued to be evident even at the smallest spatial scale of population subdivision, that of plates, with AFLPOP correctly assigning recruits back to their original plates at the remarkable level of $99.5 \%$. Through these comparative analyses, it became evi-

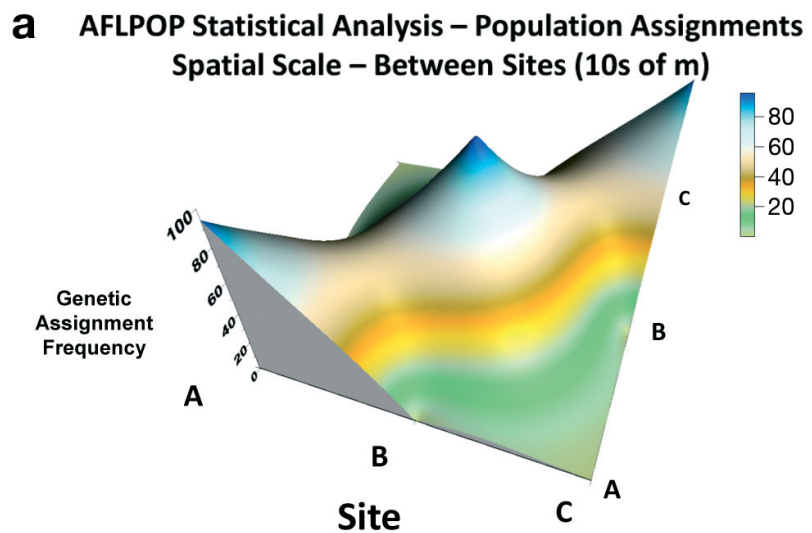

b STRUCTURE Analysis - Population Assignments
Spatial Scale - Between Sites (10s of $\mathrm{m}$ )
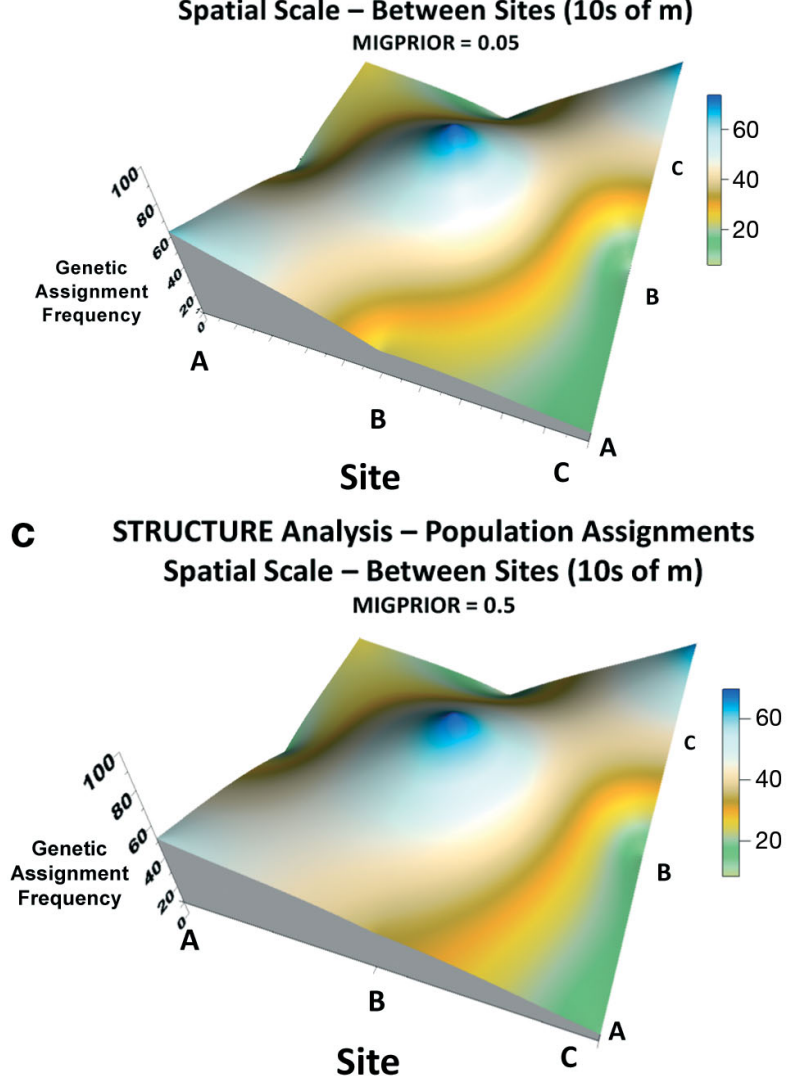

Fig. 4. Agaricia agaricites. (a) AFLPOP analyses, with assignments being considered at the spatial scale of sites (10s of meters). Data shown in percent (\%). The percent allocation of coral spat back to their original sites and populations may be found on the diagonal. The minimum log-likelihood difference used here was set to 1.0. Samples that could not be assigned to any population with a probability 10 -fold greater than the next most likely population assignment were designated 'criteria not met' (CNM). Specific CNM frequencies were: $\mathrm{A}=5.2 \%, \mathrm{~B}=2.3 \%$, and $\mathrm{C}=6.7 \%$. (b) STRUCTURE analyses, with assignments being considered at the spatial scale of sites (10s of meters). The MIGPRIOR value used for the analysis was 0.05 . The $F_{\mathrm{ST}}$ values associated with the sites were: $\mathrm{A}=0.1058, \mathrm{~B}=0.0556$, and $\mathrm{C}=0.2236$. (c) Similar to (b) but here the MIGPRIOR value used for the analysis was 0.5 .

$F_{\mathrm{ST}}$ values were the same as in (b) 
a

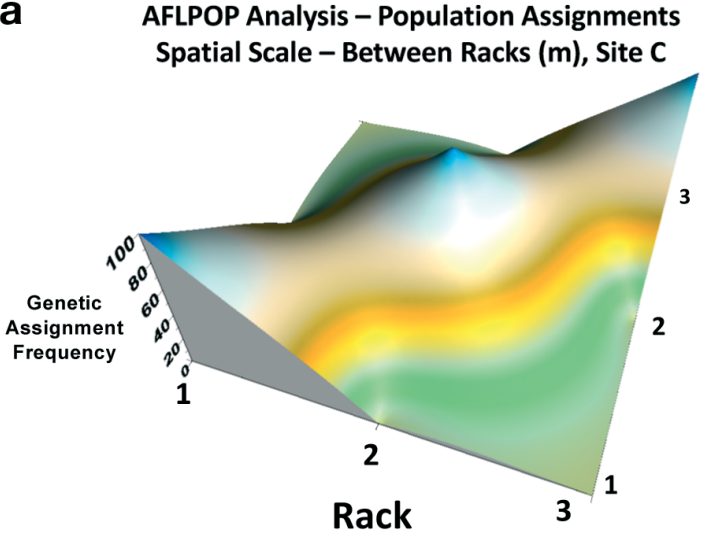

b

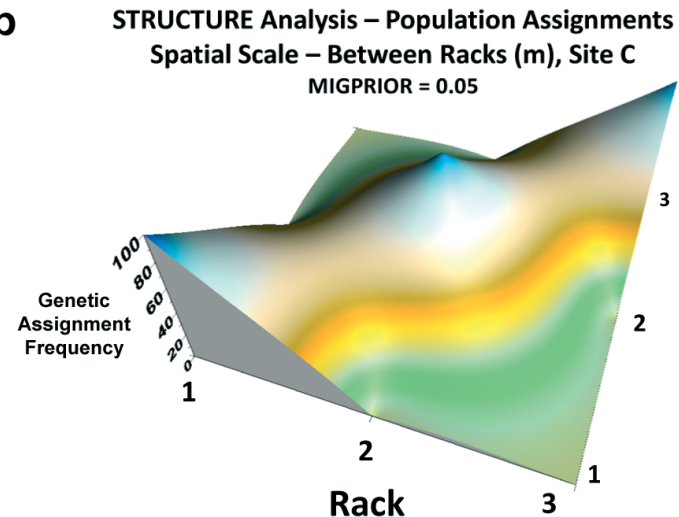

C

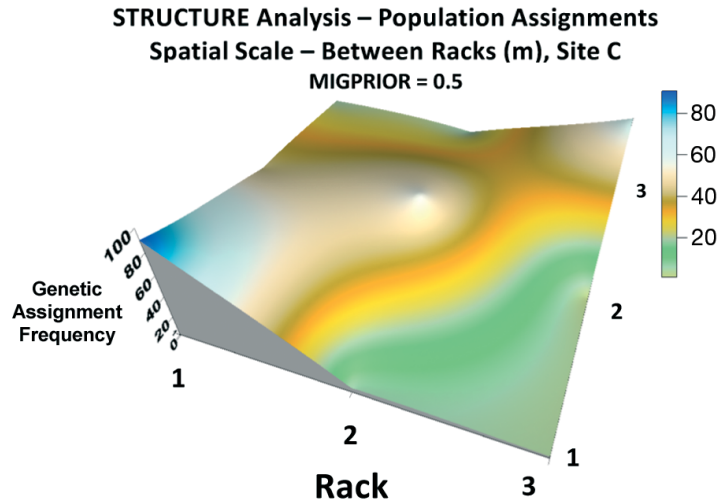

Fig. 5. Agaricia agaricites. (a) AFLPOP analyses, with assignments being considered at the spatial scale of racks within sites $(\mathrm{m})$. Data shown in percent $(\%)$. The percent allocation of coral spat back to their original sites and populations may be found on the diagonal. The minimum log-likelihood difference used here was set to 1.0. Specific CNM ('criteria not

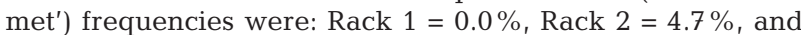
Rack $3=4.3 \%$. (b) STRUCTURE analyses, with assignments being considered at the spatial scale of sites (10s of $\mathrm{m})$. The MIGPRIOR value used for this analysis was $0.05 . F_{\mathrm{ST}}$ values associated with the racks were: $\mathrm{A} 1=0.3341, \mathrm{~A} 2=0.0902$, and A3 $=0.0013$ (see Fig. 1 for positions). (c) Similar to (b) but here the MIGPRIOR value used in the analysis was $0.5 . F_{\mathrm{ST}}$ values were identical to those cited in (b) a

AFLPOP Analysis - Population Assignments Spatial Scale - Between Plates (10s of $\mathrm{cms}$ )

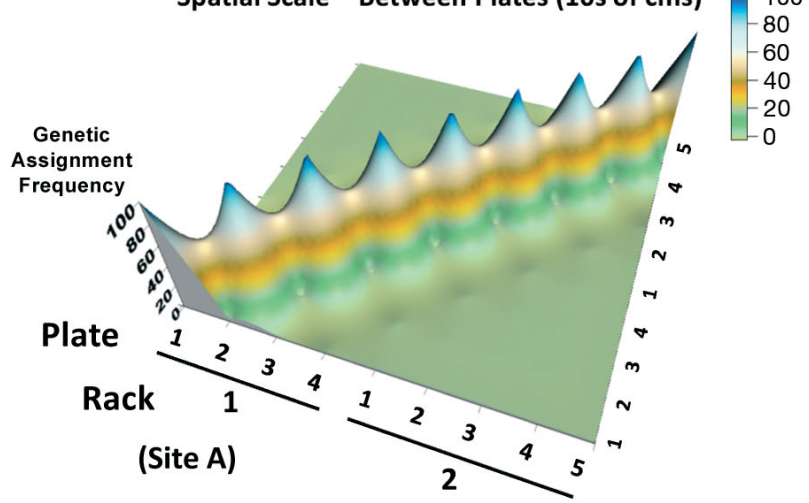

b

$$
\begin{gathered}
\text { STRUCTURE Analysis - Population Assignments } \\
\text { Spatial Scale - Between Plates (10s of cms) } \\
\text { MIGPRIOR }=0.05
\end{gathered}
$$

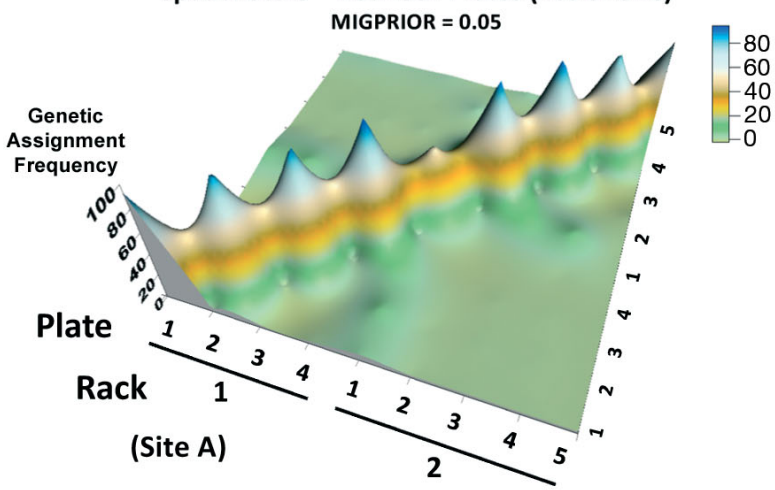

\section{STRUCTURE Analysis - Population Assignments Spatial Scale - Between Plates (10s of cms)}

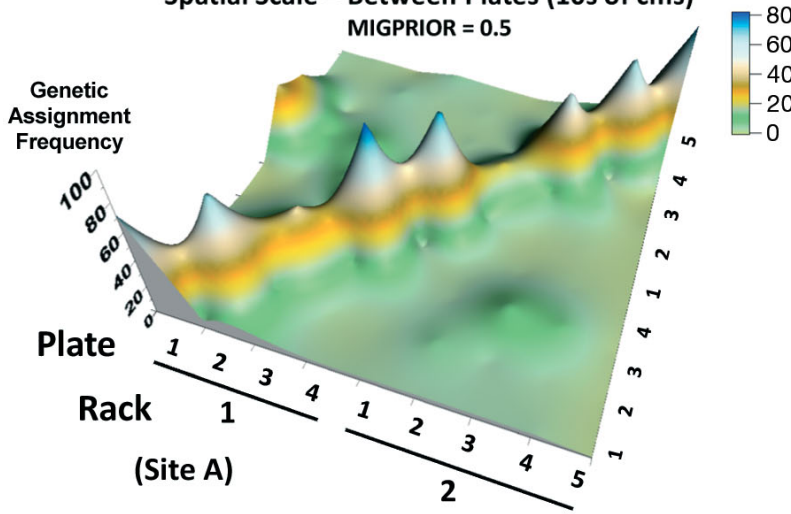

Fig. 6. Agaricia agaricites. AFLPOP analyses, with coral spat being considered at the spatial scale of plates within racks (1 and 2 , within Site $A_{i} 10$ s of $\mathrm{cm}$ ). Data shown in percent (\%). Allocation of coral spat back to their original sites and populations are shown on the diagonal. The minimum log-likelihood difference has been set at 1.0. See Table 3 for frequencies of samples that could not be assigned to any population with a probability 10 -fold greater than the next most likely population assignment, designated 'criteria not met'. (b) STRUCTURE analyses of the same data. The MIGPRIOR value used for this analysis was 0.05 . See Table 4 for $F_{\mathrm{ST}}$ values. (c) Analysis of the same data by STRUCTURE but with the MIGPRIOR value set at 0.5 
Table 3. Agaricia agaricites. AFLPOP analysis, with coral spat being considered at the spatial scale of plates within racks (1 and 2 , within Site $A_{;} 10$ s of $\mathrm{cm}$ ). Data were run with a minimum log-likelihood difference of 1.0. Coral spat that could not be assigned to any population with a probability 10 -fold greater than the next most likely population assignment were designated 'criteria not met' (CNM). Frequencies ranged from 0.3 to $1.0 \%$

\begin{tabular}{|lcc|}
\hline Site A & Plate & CNM (\%) \\
\hline Rack 1 & 1 & 0.30 \\
& 2 & 0.50 \\
& 3 & 0.03 \\
Rack 2 & 4 & -0.30 \\
& 1 & 0.40 \\
& 2 & 0.30 \\
& 3 & 0.60 \\
& 4 & 1.00 \\
& 5 & 0.00 \\
\hline
\end{tabular}

Table 4. Agaricia agaricites. STRUCTURE analyses, with coral spat being considered at the spatial scale of plates within racks (1 and 2 , within Site $A_{i} 10 \mathrm{~s}$ of $\mathrm{cm}$ ). The MIGPRIOR value used for this analysis was 0.05

\begin{tabular}{|lrr|}
\hline Site A & Plate & \multicolumn{1}{c|}{$F_{\mathrm{ST}}$} \\
\hline Rack 1 & 1 & 0.0073 \\
& 2 & 0.0001 \\
& 3 & 0.0100 \\
Rack 2 & 4 & -0.0341 \\
& 1 & 0.2910 \\
& 2 & 0.0125 \\
& 3 & 0.0217 \\
& 4 & 0.0029 \\
& 5 & 0.4702 \\
\hline
\end{tabular}

dent that STRUCTURE generally yielded more conservative values, although the average rates of selfassignment nonetheless reached $86.4 \%$ (64\% with MIGPRIOR set to 0.5), and were significant.

STRUCTURE analysis, conducted over the entire population with no population identifiers, suggested an inferred population size $(k)$ of 1 , suggesting that all sampled recruits originated from 1 homogeneous source. We believe this can be explained in that the recruits largely originated from the local population and that the structure detected within sites reflected the offspring from 1 or a few adults from the near vicinity. Without additional spatial information, STRUCTURE perceives the entire population sampled as being relatively homogenous. Once additional smaller scale spatial information is provided (sites, racks, or plates), familial structure becomes apparent. These data suggest that at least in this year's recruitment, spat were derived locally, with very little mixing in the water prior to settlement. Extreme short-distance dis- persal, particularly in brooding corals (Tioho et al. 2001), and resultant fine-scale genetic structure, are known to occur in other marine invertebrate populations (Calderon et al. 2007, Yund \& O'Neil 2000).

Agaricia agaricites is a brooder capable of selffertilization. In addition, evidence of self-seeding has been found in this species for the FGB (Brazeau et al. 2005). It is possible that other factors may have influenced our observations of fine-scale genetic structure, including kin aggregation (Veliz et al. 2006), polyembryony (Pemberton et al. 2007), and selection (Zvuloni et al. 2008). We cannot rule out any of these explanations; all of them, however, require additional factors beyond our suggestion of low dispersal with limited larval mixing to produce the observed patterns. While our study represents data from a single year's recruitment, and larval mixing and transport in other years may be greater, it does suggest that self-seeding may be important for this coral and that the potential for very fine-scale genetic structure exists. This has important implications for this species' ability to adapt to local environmental conditions.

Our apparent detection of family structure in this coral suggests that, for at least some species and perhaps particularly for brooding scleractinian corals, cryptic, small-scale genetic structure may be common. Such micro-spatial genetic structure would only be further enhanced if fertilization were successful and more common among near neighbors than distant ones, as has been documented to occur in some other species (Pennington 1985, Levitan et al. 1991, Brazeau \& Lasker 1992). The processes of both low dispersal and mating and successful fertilization between near neighbors would facilitate the selection and maintenance of local adaptations.

Little is known about the spatial scale (see Goreau et al. 1981) and genetic micro-structure of coral settlement in the field. Larvae of some corals have been observed to settle within meters of their parent colonies, suggesting that local retention and extremely short dispersal may be common in some species (Carlon \& Olson 1993, Tioho et al. 2001). In fact, Swearer et al. (2002), in a comprehensive review of many shallowwater marine species, suggests that self-recruitment may be common even among species with long development times. Here, we have chosen 3 nested levels of spatial scale to examine for these properties in coral recruits, spanning $10 \mathrm{~s}$ of meters through meters to $10 \mathrm{~s}$ of centimeters. We have used highly polymorphic genetic markers to demonstrate very fine-scale genetic structure or heterogeneity in populations of coral spat at a variety of spatial scales. These results indicate that high genetic variability can occur in coral populations, even if that recruitment is derived from reefs that are self-seeding (Brazeau et al. 2005). This, in turn, confers 
considerable adaptive ability on the part of the local populations. Such molecular and statistical techniques can also be applied to other systems to answer similar questions regarding genetic variability in populations of newly settled juveniles.

\section{Implications for adaptability to environmental perturbations}

In considering the survivability of a population with respect to environmental change, one must consider both the scale of the perturbation and the scale of the genetic structure of the population. In a previous study (Brazeau et al. 2005), using similar DNA molecular genetic analyses and statistical analyses, we demonstrated that the adult Agaricia agaricites population at FGB is completely distinct from the populations on Conch Reef and Crocker Reef (Florida Keys) and from the populations off the Family Islands (Bahamas). We also demonstrated that the coral spat settling on the FGB exhibited a very high genetic affinity to the adults on that reef and almost no affinity to those in the Florida Keys or the Bahamas, indicating that this brooding species of coral on the FGB is most likely selfseeded.

In the present study, upon closer examination, we found that coral spat settling in this area of the West FGB is highly heterogeneous and structured at all 3 spatial scales considered. What are the implications of these findings when considered in the context of the rapidly changing physico-chemical environment of our world's oceans in the 21st century? At this time, 3 major perturbations are of concern: (1) increasing seawater temperatures due to climate change/global warming and resultant bleaching, causing mass mortality of corals world-wide; (2) increasing incidence of coral diseases, causing similar mass mortalities and, in some cases, local extinction and near global extinction of certain coral species (e.g. Caribbean Acropora species); and (3) acidification of the world's oceans caused by an increase in the concentration of $\mathrm{CO}_{2}$ in the earth's atmosphere, predicted to have a highly detrimental effect on the growth and survivorship of corals dependent upon the precipitation of calcium carbonate. All of these are macro-scale perturbations. Threat to the survivorship of the community will not be affected by variance in genetic structure at the scales considered in the present study. Individuals within this population on this reef will either survive or not survive a massive, broad-scale perturbation of this type, irrespective of the spatial scale of genetic structure (notwithstanding, perhaps, depth). Differences in the genetic structure observed between the FGB and the Florida Keys and the Bahamas, however, suggest that there may well be sufficient differences between populations in these regions to manifest variation in the response of their coral populations to a macro-scale environmental perturbation, such as seawater temperature change.

The fine-scale differences in genetic structure observed here would suggest, however, that even small areas (the FGB for example) may contain considerable genetic diversity. Thus, large-scale disturbances must be evaluated, not only in terms of the extent of devastation, but also of the variation in damage among sites. Should the results we observed here be valid across years, the data would suggest that for some species even the small remnant populations left behind may contain significant genetic diversity to provide some hope of recovery. Thus, it would appear that, given highly structured populations like the ones we have studied here, the nature of large-scale environmental perturbations may be quite important in determining the long-term impacts on the population.

Acknowledgements. We thank A. D. Atchison for processing the coral plates and pre-processing the coral DNA samples. Many thanks to the divers who assisted in sample collection: J. Elliott, S. Gittings, D. Hagman, E. Hickerson, and S. Kirchhoff; the crew of the NOAA RV 'Ferrel'-E. Byron, A. Creswell, R. Rogers, and B. Cowden; and the crew of the MV 'Fling' - K. Bush, P. Coombs, J. Dibble, and Travis Kilpatrick. This project was funded by the NOAA, the NOAA Flower Garden Banks National Marine Sanctuary, and the Louisiana Universities Marine Consortium (LUMCON).

\section{LITERATURE CITED}

Adjeroud M, Penin L, Carroll A (2007) Spatio-temporal heterogeneity in coral recruitment around Moorea, French Polynesia: implications for population maintenance. J Exp Mar Biol Ecol 341:204-218

Amar KO, Douek J, Rabinowitz C, Rinkevich B (2008) Employing of the amplified fragment length polymorphism (AFLP) methodology as an efficient population genetic tool for symbiotic cnidarians. Mar Biotechnol 10:350-357

Aronson RB, Precht WF, Murdoch TJT, Robbart ML (2005) Long-term persistence of coral assemblages on the Flower Garden Banks, northwestern Gulf of Mexico: implications for science and management. Gulf Mex Sci 23:84-94

Atrigenio MP, Alino PM (1996) Effects of the soft coral Xenia puertogalerae on the recruitment of scleractinian corals. J Exp Mar Biol Ecol 203:179-189

Ayre DJ, Hughes TP (2000) Genotypic diversity and gene flow in brooding and spawning corals along the Great Barrier Reef, Australia. Evolution 54:1590-1605

Baggett LS, Bright TJ (1985) Coral recruitment at the East Flower Garden Reef (northwestern Gulf of Mexico). Proc 5th Int Coral Reef Congr 4:379-384

Boyce MS (1992) Population viability analysis. Annu Rev Ecol Syst 23:481-506

Brazeau DA, Lasker HR (1992) Reproductive success in the Caribbean octocoral Briareum asbestinum. Mar Biol 114: $157-163$ 
Brazeau DA, Sammarco PW, Gleason DF (2005) A multi-locus genetic assignment technique to assess sources of Agaricia agaricites larvae on coral reefs. Mar Biol 147:1141-1148

Brunel T, Boucher J (2006) Environmental determinism of recruitment variability - a macroecological approach applied to northeastern exploited fish populations. Ifremer, Plouzane

Calderon I, Ortega N, Duran S, Becerro M, Pascual M, Turon $X$ (2007) Finding the relevant scale: clonality and genetic structure in a marine invertebrate (Crambe crambe, Porifera). Mol Ecol 16:1799-1810

Campbell D, Duchesne P, Bernatchez L (2003) AFLP utility for population assignment studies: analytical investigation and empirical comparison with microsatellites. Mol Ecol 12:1979-1991

Carleton JH, Sammarco PW (1987) Effects of substratum irregularity on success of coral settlement: quantification by geomorphological techniques. Bull Mar Sci 40:85-98

Carlon DB, Olson RR (1993) Larval dispersal distance as an explanation for adult spatial pattern in two Caribbean reef corals. J Exp Mar Biol Ecol 173:247-263

Connell JH, Hughes TP, Wallace CC (1997) A 30-year study of coral abundance, recruitment, and disturbance at several scales in space and time. Ecol Monogr 67:461-488

- Cowen RK, Paris CB, Srinivasan A (2006) Scaling of connectivity in marine populations. Science 311:522-527

Duchesne P, Bernatchez L (2002) AFLPOP: a computer program for simulated and real population allocation, based on AFLP data. Mol Ecol Notes 2:380-383

Fahrig L (2002) Effect of habitat fragmentation on the extinction threshold: a synthesis. Ecol Appl 12:346-353

Gilmour JP (2002) Substantial asexual recruitment of mushroom corals contributes little to population genetics of adults in conditions of chronic sedimentation. Mar Ecol Prog Ser 235:81-91

Goreau NI, Goreau TJ, Hayes RL (1981) Settling, survivorship, and spatial aggregation in planulae and juveniles of the coral Porites porites (Pallas). Bull Mar Sci 31:424-435

Hagman DK, Gittings SR, Deslarzes KJP (1998) Timing, species participation, and environmental factors influencing annual mass spawning at the Flower Garden Banks (northwestern Gulf of Mexico). Gulf Mex Sci 2:170-179

Harriott VJ, Banks SA (1995) Recruitment of scleractinian corals in the Solitary Islands marine reserve, a high latitude coral-dominated community in eastern Australia. Mar Ecol Prog Ser 123:155-161

He T, Krauss SL, Lamont BB, Miller BP, Enright NJ (2004) Long-distance seed dispersal in a metapopulation of Banksia hookeriana inferred from a population allocation analysis of amplified fragment length polymorphism data. Mol Ecol 13:1099-1109

Hughes TP, Tanner JE (2000) Recruitment failure, life histories, and long-term decline of Caribbean corals. Ecology 81:2250-2263

> Hughes TP, Baird A, Dinsdale E, Moltschaniwskyi M, Pratchett M, Tanner J, Willis BL (1999) Patterns of recruitment and abundance of corals along the Great Barrier Reef. Nature 397:59-63

Knowlton N, Jackson JBC (1993) Inbreeding and outbreeding in marine invertebrates. In: Thornhill NW (ed) Natural history of inbreeding and outbreeding. University of Chicago Press, Chicago, IL

Lasker HR, Kim K, Coffroth MA (1998) Production, settlement, and survival of plexaurid gorgonian recruits. Mar Ecol Prog Ser 162:111-123

Lecchini D, Galzin R (2003) Influence of pelagic and benthic, biotic and abiotic, stochastic and deterministic processes on the dynamics of auto-recruitment of coral reef fish: a review. Cybium 27:167-184

Levins R (1968) Evolution in changing environments. Princeton University Press, Princeton, NJ

Levitan DR, Sewell MA, Chia FC (1991) Kinetics of fertilization in the sea urchin Strongylocentrotus franciscanus: interaction of gamete dilution, age, and contact time. Biol Bull 181:371-378

Mace GM, Lande R (1991) Assessing extinction threats: toward a re-evaluation of IUCN threatened species categories. Conserv Biol 5:148-157

Maida M, Sammarco PW, Coll JC (2001) Effects of soft corals on scleractinian coral recruitment. II. Allelopathy, coral spat survivorship, and reef community structure. PSZNI: Mar Ecol 22:397-414

Manel S, Gaggiotti OE, Waples RS (2005) Assignment methods: matching biological questions with appropriate techniques. Trends Ecol Evol 20:136-142

McGuire MP (1998) Timing of larval release by Porites astreoides in the northern Florida Keys. Coral Reefs 17: 369-375

Moberg PE, Burton RS (2000) Genetic heterogeneity among adult and recruit red sea urchins, Strongylocentrotus franciscanus. Mar Biol 136:773-784

> Paetkau D, Slade R, Burden M, Estoup A (2004) Genetic assignment methods for the direct, real-time estimation of migration rate: a simulation-based exploration of accuracy and power. Mol Ecol 13:55-65

Pattengill-Semmens CV, Gittings SR (2003) A rapid assessment of the Flower Garden Banks National Marine Sanctuary (stony corals, algae and fishes). Atoll Res Bull 496: 500-511

Pemberton AJ, Hansson LJ, Craig SF, Hughes RN, Bishop JDD (2007) Microscale genetic differentiation in a sessile invertebrate with cloned larvae: investigating the role of polyembryony. Mar Biol 153:71-82

Pennington JT (1985) The ecology of fertilization of echinoid eggs: the consequences of sperm dilution, adult aggregation, and synchronous spawning. Biol Bull 169:417-430

Pineda J, Hare NA, Sponaugle S (2007) Larval transport and dispersal in the coastal ocean and consequences for population connectivity. Oceanography 20:22-39

Pritchard JK, Stephens M, Donnelly P (2000) Inference of population structure using multilocus genotype data. Genetics 155:945-959

Quinn NJ, Kojis BL (2005) Patterns of sexual recruitment of acroporid coral populations on the West Fore Reef at Discovery Bay, Jamaica. Rev Biol Trop 53:83-90

Riegl B, Manfrino C, Brandt M, Hoshino K (2003) Assessment of the coral reefs of the Turks and Caicos Islands. Part 1: stony corals and algae. Atoll Res Bull 496:460-479

Sammarco PW (1980) Diadema and its relationship to coral spat mortality: grazing, competition, and biological disturbance. J Exp Mar Biol Ecol 45:245-272

Sammarco PW (1987) A comparison of ecological processes on coral reefs of the Caribbean and the Great Barrier Reef. In: Birkeland C (ed) Comparison between Atlantic and Pacific tropical marine coastal ecosystems: community structure, ecological processes, and productivity. UNESCO Rep Mar Sci 46:127-166

Sammarco PW (1991) Geographically specific recruitment and post-settlement mortality as influences on coral community structure: the cross-shelf transplant experiment. Limnol Oceanogr 36:496-514

Sammarco PW (2004) Larval dispersal and recruitment processes in Great Barrier Reef corals: analysis and synthesis. In: Sammarco PW, Heron ML (eds) The biophysics of 
marine larval dispersal. AGU Press, Washington, DC, p 35-72

Sammarco PW, Andrews JC (1988) Localized dispersal and recruitment in Great Barrier Reef corals: the Helix experiment. Science 239:1422-1424

Sammarco PW, Atchison AD, Boland GS (2004) Offshore oil and gas platforms and expansion of coral communities within the northern Gulf of Mexico. Mar Ecol Prog Ser 280:129-143

Severance EG, Karl SA (2006) Contrasting population genetic structures of sympatric, mass-spawning Caribbean corals. Mar Biol 150:57-68

Shearer TL, Coffroth MA (2006) Genetic identification of Caribbean scleractinian coral recruits at the Flower Garden Banks and the Florida Keys. Mar Ecol Prog Ser 306: 133-142

Smith PJ, McVeagh SM, Won Y, Vrijenhoek RC (2004) Genetic heterogeneity among New Zealand species of hydrothermal vent mussels (Mytilidae: Bathymodiolus). Mar Biol 144:537-545

Swearer SE, Shima JS, Hellberg ME, Thorrold SR and others (2002) Evidence of self-recruitment in demersal marine populations. Bull Mar Sci 70:251-271

Taylor MS, Hellberg ME (2003) Genetic evidence for local

Editorial responsibility: Hans Heinrich Janssen,

Oldendorf/Luhe, Germany retention of pelagic larvae in a Caribbean reef fish. Science 299:107-109

Tioho H, Tokeshi M, Nojima S (2001) Experimental analysis of recruitment in a scleractinian coral at high latitude. Mar Ecol Prog Ser 213:79-86

Veliz D, Duchesne P, Bourget E, Bernatchez L (2006) Genetic evidence for kin aggregation in the intertidal acorn barnacle (Semibalanus balanoides). Mol Ecol 15:4193-4202

> Vermeij MJA, Sandin SA (2008) Density-dependent settlement and mortality structure the earliest life phases of a coral population. Ecology 89:1994-2004

Vos P, Hogers R, Bleeker M, Reijans M and others (1995) AFLP: a new technique for DNA fingerprinting. Nucleic Acids Res 23:4407-4414

Watts RJ, Johnson MS, Black R (1990) Effect of recruitment on genetic patchiness in the urchin, Echinometra mathaei, in western Australia. Mar Biol 44:213-232

Yund PO, O'Neil PG (2000) Microgeographic genetic differentiation in a colonial ascidian (Botryllus schlosseri) population. Mar Biol 137:583-588

Zvuloni A, Mokady O, Al-Zibdah M, Bernardi G, Gaines SD, Abelson A (2008) Local scale genetic structure in coral populations: a signature of selection. Mar Pollut Bull 56: $430-438$

Submitted: May 18, 2010; Accepted: December 15, 2010

Proofs received from author(s): March 16, 2011 